\title{
Morphology of the spermathecae of twelve species of Triatominae (Hemiptera, Reduviidae) vectors of Chagas disease
}

\author{
Juliana Damieli Nascimento ${ }^{\mathrm{a}}$, Aline Rimoldi Ribeiro ${ }^{\mathrm{a}}$, Larissa Aguiar Almeida ${ }^{\mathrm{b}}$, \\ Jader de Oliveira $^{\mathrm{b}}$, Vagner José Mendonça ${ }^{\mathrm{b}, \mathrm{d}}$, Mário Cilense ${ }^{\mathrm{c}}$, João Aristeu da Rosa ${ }^{\mathrm{b}, *}$ \\ a Universidade Estadual de Campinas (Unicamp), Campinas, São Paulo, Brazil \\ b Universidade Estadual Paulista (UNESP), Faculdade de Ciências Farmacêticas, Araraquara \\ c Universidade Estadual Paulista (UNESP), Instituto de Química, Araraquara \\ d Universidade Federal do Piauí, Teresina, Brazil
}

\section{A R T I C L E I N F O}

\section{Keywords:}

Triatominae

Morphology

Spermathecae

\begin{abstract}
A B S T R A C T
Trypanosoma cruzi, the etiological agent of Chagas disease, is transmitted by triatomines that have been described in a large number of studies. Most of those studies are related to external morphology and taxonomy, but some biochemical, genetic and physiological studies have also been published. There are a few publications in the literature about the internal organs of Triatominae, for instance the spermathecae, which are responsible for storing and maintaining the viability of the spermatozoids until the fertilization of the oocytes. This work aims to study the spermathecae of twelve species of triatomines obtained from the Triatominae Insectarium of the Faculty of Pharmaceutical Sciences, UNESP, Araraquara, using optical microscopy and scanning electron microscopy. The spermathecae of the twelve species studied showed three morphological patterns: a) $P$. herreri sn, P. lignarius, P. megistus, Triatoma brasiliensis, T. juazeirensis, T. sherlocki and T. tibiamaculata have spermathecae with a thin initial portion and an oval-shaped final portion; b) $R$. montenegrensis, $R$. nasutus, $R$. neglectus, $R$. pictipes and $R$. prolixus have tubular and winding spermathecae; c) $T$. infestans has oval spermathecae. In addition to the three morphological patterns, it was noted that each of the twelve species has particular features that differentiate them.
\end{abstract}

\section{Introduction}

Chagas disease represents a serious public health problem for the population of Latin America. It is estimated eight million people are infected with Trypanosoma cruzi and 25 million people live in risk zones. Transmission mainly occurs through the feces of insects of the subfamily Triatominae (Galvão, 2014; WHO, 2017).

The importance of triatomines as vectors of $T$. cruzi is the most common justification for their study. Existing research covers mainly external morphology, biology, biochemistry and physiology, but there are a few publications on the internal morphology of these insects. This work addresses this gap in the literature by presenting a study of the spermathecae of 12 species of Triatominae.

The spermathecae are responsible for storing the spermatozoids released at the moment of the copulation until the fertilization of the oocytes, which are developed in the ovaries. When they are mature, the oocytes begin their journey towards oviposition, moving down through the lateral oviducts until reaching the common oviduct, where they are fertilized by the spermatozoids located in the spermathecae. As soon as the oocytes pass through the common oviduct, the spermathecae inject the stored spermatozoid and fertilize the egg, which is released by contractions in the genital chamber and other external structures of the female reproductive system. The lateral oviducts and the common oviduct have several folds in their muscles to ensure good clearance and thus allow the oocyte to pass (Pérez, 1969; Barth, 1973).

After the successful copulation, the female can store the spermatozoids for months or years, but little is known about how the spermatozoids are maintained. The spermatozoids have secretion sheaths that enhance their mobility, but inside the spermathecae they encapsulate themselves and lose such sheaths. As a result, they remain motionless during storage and are activated only at the moment oocytes are fertilized, but the activation path is still unknown (Vöcking et al., 2013). In this study it was possible to completely observe the spermathecae full of spermatozoids when the female was fed and left during a week with a male for the complete fertilization. However, it was not possible to observe the physiological storage conditions of the fertilized

\footnotetext{
* Corresponding author.

E-mail addresses: judamieli@gmail.com (J.D. Nascimento), line2rimoldi@gmail.com (A.R. Ribeiro), lari.almeida01@gmail.com (L.A. Almeida), jdr.oliveira@hotmail.com (J. de Oliveira), vag_jose@yahoo.com.br (V.J. Mendonça), mcilense@iq.unesp.br (M. Cilense), joaoaristeu@gmail.com (J.A. da Rosa).
} 
spermathecae.

The twelve species studied belong to three genera of major epidemiology and taxonomy importance: Panstrongylus, Rhodnius and Triatoma. Panstrongylus megistus was found in one of the largest metropolitan areas of Latin America in 2011; Rhodnius neglectus was collected on palm trees in downtown Monte Alto city in 2013; and Triatoma maculata was found in an air-conditioner box in a modern brick-built apartment block in 2016 (Carvalho et al., 2013; Rimoldi et al., 2016; Ricardo-Silva et al., 2016).

The objective of this paper is to contribute to and amplify the morphological study of spermathecae of $P$. herreri sn, $P$. lignarius, $P$. megistus, Rhodnius montenegrensis, $R$. nasutus, $R$. neglectus, $R$. pictipes, $R$. prolixus, Triatoma brasiliensis, T. infestans, T. juazeirensis, T. sherlocki and T. tibiamaculata. It also suggests that spermathecae can be used as a taxonomic feature for the identification of triatomines.

\section{Methods}

The species of triatomines studied were obtained from the colonies maintained in the Triatominae Insectarium of the Faculty of Pharmaceutical Sciences, São Paulo State University (UNESP), Araraquara, Brazil (Table 1). The specimens were collected in sylvatic, peridomestic and domestic environments in different states of Brazil and Colombia.

Both adult males and adult females were placed in glass jars and fed for a week prior to the procedures. Only the females in the glass jars were used in this study.

\subsection{Optical microscopy}

In order to study their reproductive system, the insects were killed with $\mathrm{CO}_{2}$ and placed on a Petri dish with entomological pins. The connectives were cut using scissors and with the aid of tweezers the tergites were removed in such a way as to allow fat body visualization. A Ringer's solution for insects (7.5 g of NaCl; $2.38 \mathrm{~g}$ of $\mathrm{Na}_{2} \mathrm{HPO}_{4} ; 72 \mathrm{~g}$ of $\mathrm{KH}_{2} \mathrm{PO}_{4}$ per $1000 \mathrm{~mL}$ of distilled water) was also used. After the fat body was removed with the aid of tweezers, the intestine, esophagus and the final portion of the rectal ampoule were pinched off, which allowed the visualization of the reproductive system.

Optical microscopy images were generated using a LEICA MZ APO stereoscopic microscope and analyzed through the Motic Advanced 3.2 plus system. For this study a total of 60 samples were taken, five for each species.

Table 1

Origin of species and their respective triatomines' colonies used in the study.

\begin{tabular}{|c|c|c|c|}
\hline Species & Code & Origin & $\begin{array}{l}\text { Year of colony } \\
\text { establishment }\end{array}$ \\
\hline P. lignarius & 012 & Fiocruz/RJ & 2008 \\
\hline P. megistus & 019 & $\begin{array}{l}\text { Faculdade de Medicina de } \\
\text { Ribeirão Preto }\end{array}$ & 1984 \\
\hline R. montenegrensis & 088 & Montenegro/RO & 2008 \\
\hline R. nasutus & 053 & $\begin{array}{l}\text { Patú, Messias Tarcino e } \\
\text { Almino Afonso }\end{array}$ & 1983 \\
\hline R. neglectus & 058 & Pitangueiras/SP & 1982 \\
\hline$R$. pictipes & 071 & Jacundá/PA & 1983 \\
\hline R. prolixus & 076 & $\begin{array}{l}\text { Instituto Nacional de Salud, } \\
\text { Bogotá, Colômbia }\end{array}$ & 1983 \\
\hline T. braziliensis & 101 & Oeiras/PI & 2008 \\
\hline T. infestans & 123 & Frutal/MG & 1982 \\
\hline T. juazeirensis & 206 & Juazeiro/BA & 2010 \\
\hline T. sherlocki & 173 & Santo Inácio/BA & 2007 \\
\hline T. tibiamaculata & 196 & Fiocruz/RJ & 1984 \\
\hline
\end{tabular}

\subsection{Scanning electron microscopy}

To obtain images through scanning electron microscopy (SEM), samples were dissected as described above. To preserve the spermathecae, the cuts were made in the insertions of the lateral oviducts with common oviducts and genital chamber and fixed on an aluminum support with glutaraldehyde $20 \%$. The samples were metallized for $80 \mathrm{~s}$ in $10 \mathrm{~mA}$ and examined using a scanning electron microscope (Topcon SM 300, Topcon Corporation, Hasunuma-Cho, Tokyo Itabashi-ku, Japan) at the Institute of Chemistry of UNESP, Araraquara, according to Rosa et al. (1999). For this study 36 samples were used, three samples for each species.

\section{Results}

In all the twelve adult female species of triatomines the structures of the reproductive system were found. As the spermathecae are an expansion of the common oviduct, only the abdomen was dissected. Fig. 1 shows the structures of the reproductive system and spermathecae.

The study of the female spermathecae of $P$. lignarius, $P$. megistus, $R$. montenegrensis, $R$. nasutus, $R$. neglectus, $R$. pictipes, $R$. prolixus, T. brasiliensis, T. infestans, T. juazeirensis, T. sherlocki and T. tibiamaculata showed distinct characters among them when compared by optical microscopy and scanning electron microscopy (Table 2).

Spermathecae of $P$. lignarius and $P$. megistus have elongated body with oval-shaped final portions when observed by optical microscopy (Fig. 2A and B). However, when observed by scanning electron microscopy, it is possible to note that the spermathecae of $P$. lignarius are thinner and more elongated when compared to the ones of $P$. megistus, which present flattened bodies (Fig. 3A and B).

The species of the genus Rhodnius have elongated and cylindrical spermathecae, but by means of both optical microscopy and scanning electron microscopy it is possible to notice the differences in size and anatomical disposition. The spermathecae of $R$. montenegrensis (Figs. 2 $\mathrm{C}$ and $3 \mathrm{C}$ ) have a little sinuous line at the final portion facing towards the posterior part of the body, while those of $R$. nasutus (Figs. $2 \mathrm{D}$ and 3 D) are all wrapped. On Rhodnius neglectus (Figs. $2 \mathrm{E}$ and $3 \mathrm{E}$ ) the final portion of the spermathecae faces towards the anterior part of the body. Rhodnius pictipes (Figs. $2 \mathrm{~F}$ and $3 \mathrm{~F}$ ) has several curves along its body and on $R$. prolixus (Figs. $2 \mathrm{G}$ and $3 \mathrm{G}$ ) the final portion of the spermathecae points to the common oviduct.

The spermathecae of five species of Triatoma have as a common characteristic the thin initial portions and oval-shaped final portions (Figs. 2 and 3). The spermathecae of T. brasiliensis are thin at their initial portion and oval-shaped at the final one; they are partially covered by the common oviduct and the spermatheca on the left has a narrowing that initiates the oval portion (Fig. $2 \mathrm{H}$ ). By scanning electron microscopy it was possible to observe the sharp narrowing at the early oval portion of the left spermatheca (Fig. $3 \mathrm{H}$ ).

The spermathecae of $T$. infestans (Figs. 2 I and 3 I) have a thin insertion in the common oviduct with considerable oval bodies. When they are observed by optical microscopy and scanning electron microscopy, it can be noted that the oval bodies overlap the thin insertions of the spermathecae in the common oviduct.

The spermathecae of $T$. juazeirensis (Figs. $2 \mathrm{~J}$ and $3 \mathrm{~J}$ ) have thin initial portions and oval-shaped final portions, but the latter are not overlapped by the common oviduct. Scanning electron microscopy shows that the insertions on the spermathecae are thinner when compared to the other species of Triatoma (Fig. 2).

The two spermathecae of $T$. sherlocki are distinct: one possesses thin initial portion and sharp narrowing in the middle of the body, which originates the final portion with oval shape; the other is thin with ovalshaped body (Fig. 2K).

The spermathecae of T. tibiamaculata (Figs. $2 \mathrm{~L}$ and $3 \mathrm{~L}$ ) have thin insertions in the common oviduct, thin and elongated bodies with ovalshaped terminal portions, similar to $P$. lignarius and $P$. megistus, but 


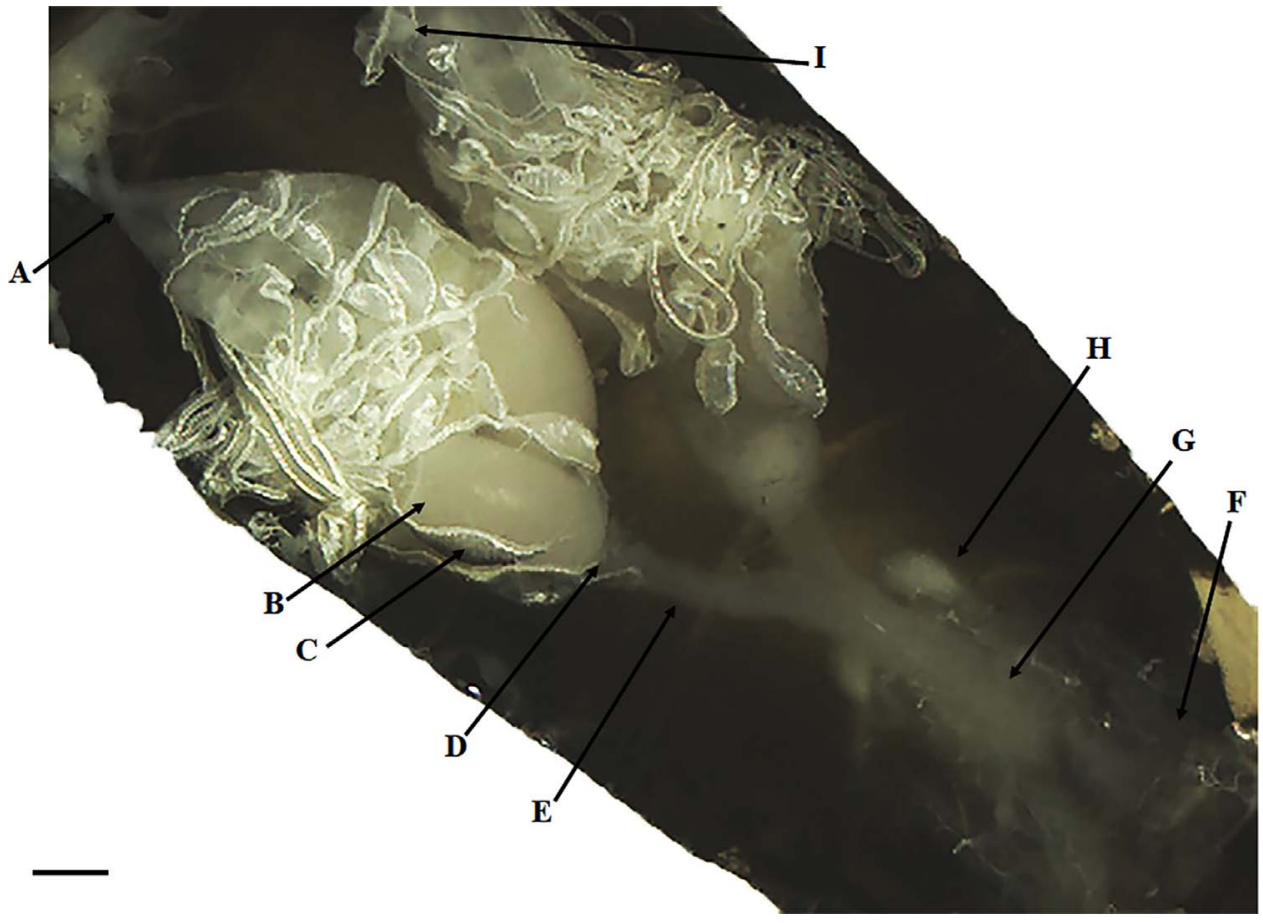

Fig. 1. Organs of the female reproductive system of T. infestans through optical microscopy, 5X (A): Terminal Filament; (B): Oocyte; (C): Ovarioles; (D): Calxy; (E): Lateral oviduct; (F): Accessory gland; (G): Genital chamber; (H): Spermathecae; (I): Fat body. The bar represents $10 \mu \mathrm{m}$. larger.

\section{Discussion}

Chagas first observed the vector-borne capacity of triatomines in his description of the protozoan $T$. cruzi. Several species are not only able to disperse it but are also high-skilled vectors, so currently the biggest challenge is to control the vector-borne transmission and propose surveillance models that can help inhibit the sylvatic transmission cycle (Galvão, 2014).

Triatomines are identified based on their external morphology, but molecular, cytogenetic and biochemical studies can support the classical taxonomy to provide the correct identification of the specimens (Querido et al., 2013; Gardim et al., 2014; Sousa et al., 2016).

The spermatophore is a proteic capsule produced by males which involves the spermatozoids. At the moment of the copulation, the spermatophore is transferred to the female and has the function of nourishing, also ensuring that the spermatozoids can reach the spermathecae. It is believed that spermatophores differ in size, shape and structure, so they can be considered specific markers for the species (Davey, 1958). Pereira-Lourenço et al. (2013) point out that the spermatophore of $R$. neglectus has a stick shape, while that of $T$. infestans has an ovoid shape. These forms resemble the spermathecae of these two species, since the spermathecae of $R$. neglectus are elongated and those of $T$. infestans are completely oval shaped.

Considering their spermathecae, three morphological patterns could be identified in the twelve species studied: a) P. lignarius, $P$. megistus, $T$. brasiliensis, T. juazeirensis, T. sherlocki and T. tibiamaculata showed spermathecae with thin initial portion and oval-shaped final portion; $b$ ) $R$. montenegrensis, $R$. nasutus, $R$. neglectus, $R$. pictipes and $R$. prolixus have tubular and winding spermathecae; c) T. infestans is the only one having completely oval-shaped spermathecae.

Morphological differences were noted not only among the three genera studied but also for each of the twelve species when observed through optical microscopy or scanning electron microscopy, including close species such as $R$. neglectus and $R$. prolixus. Although $P$. lignarius, $P$. megistus and T. tibiamaculata do not present significant differences in relation to the shape of their spermathecae, differences in size can be seen in the results of this study.

According to Justi et al. (2014), P. megistus and T. tibiamaculata are easily differentiated through morphological characteristics; however, these species are phylogenetically close and form sister taxa. Through Bayesian analysis of mitochondrial markers (cytochrome b, cytochrome oxidase I, and 16S rDNA), these two species were considered sisters with $99 \%$ of reliability, even though they belong to different genera (Gardim et al., 2014). Therefore, these works show that there are

Table 2

Characteristics of the spermathecae of 12 Triatominae species obtained by optical microscopy.

\begin{tabular}{|c|c|c|}
\hline Species & Common characteristics & Different characteristics \\
\hline P. lignarius & Thin initial portion Oval-shaped final portion & Longer and thinner when compared to $P$. megistus \\
\hline P. megistus & Thin initial portion Oval-shaped final portion & Oviduct common with short \\
\hline R. montenegrensis & Tubular and sinuous & Sinuous and facing towards the posterior part of the body \\
\hline R. nasutus & Tubular and sinuous & Wrapped \\
\hline R. neglectus & Tubular and sinuous & Final portion facing towards the anterior part of the body \\
\hline R. pictipes & Tubular and sinuous & Sinuous and elongated body \\
\hline R. prolixus & Tubular and sinuous & Final portion facing towards the common oviduct \\
\hline T. brasiliensis & Thin initial portion Oval-shaped final portion & Partially covered by the common oviduct. Abrupt narrowing at the beginning of the oval-shaped portion \\
\hline T. infestans & Oval-shaped body & Completely oval-shaped \\
\hline T. juazeirensis & Thin initial portion Oval-shaped final portion & Final portion facing towards the ventral part \\
\hline T. sherlocki & Thin initial portion Oval-shaped final portion & Abrupt narrowing in both spermathecae \\
\hline T. tibiamaculata & Thin initial portion Oval-shaped final portion & Similar to $P$. lignarius and P. megistus, but larger \\
\hline
\end{tabular}



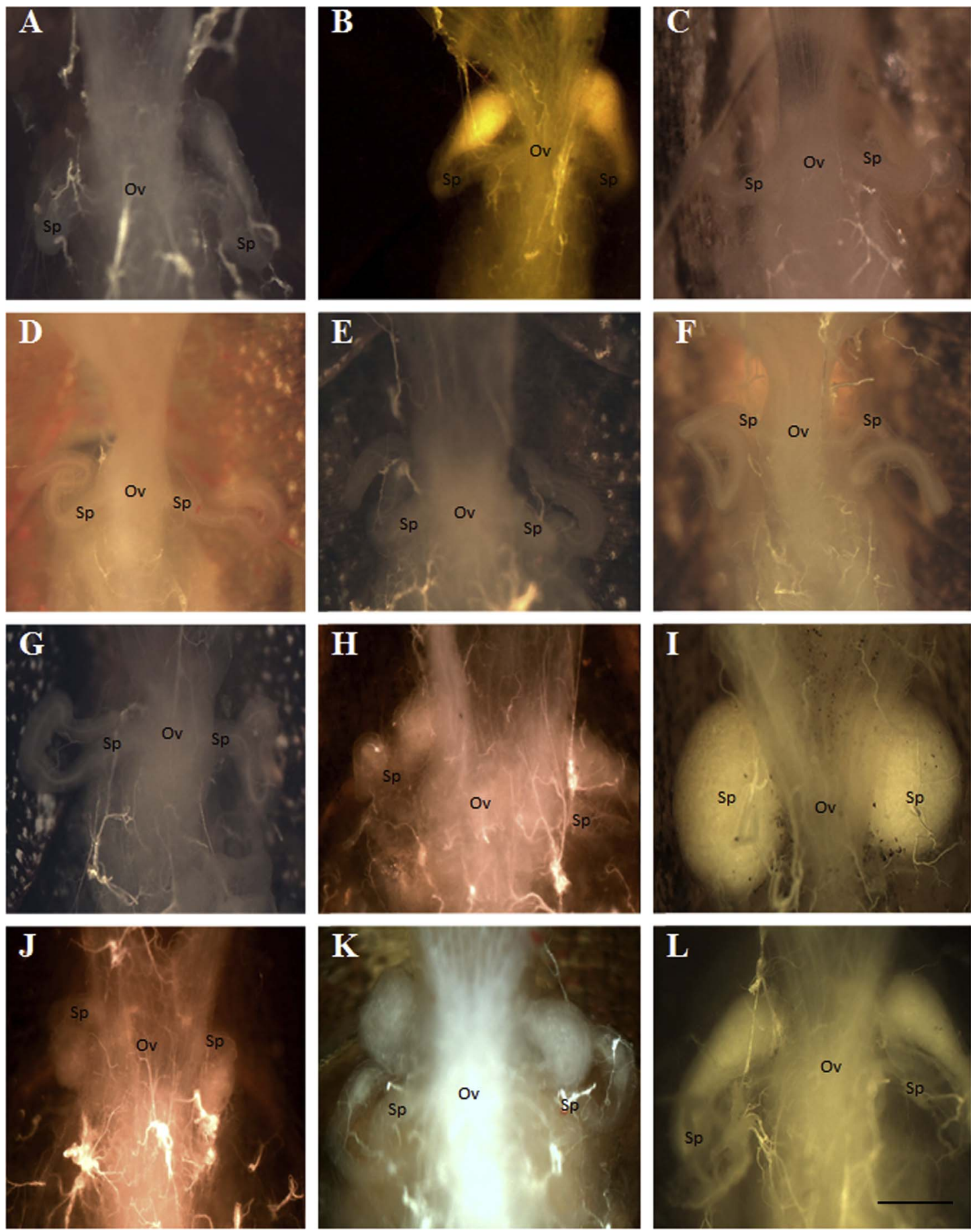

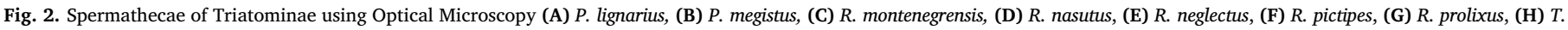
brasiliensis, (I) T. infestans, (J) T. juazeirensis, (K) T. sherlocki, (L) T. tibiamaculata. The bar represents $10 \mu \mathrm{m}$, common oviduct (Ov), spermathecae (Sp).

phylogenetic similarities between $P$. megistus and T. tibiamaculata.

Although the species $P$. megistus and T. tibiamaculata have distinct morphology, some morphological patterns are similar, as observed in fifth-instar female nymphs showing similarities on the eighth ventral segment structures, as well as between sensilla (Rosa et al., 1992). Therefore, the study of their spermathecae reveals a morphological pattern, the only differences being related to size.

Some species in this work are considered morphologically close, for instance $T$. brasiliensis and T juazeirensis. For a long time, species of the complex $T$. brasiliensis were considered a chromatic variation of $T$. brasiliensis, as it is the case of T. juazerensis, which was accepted as a new species after a taxonomic revision that took into account all morphological, biological, genetic and ecological differences among the members of the complex (Costa and Felix, 2007; Costa et al., 2013). Despite the morphological similarity, the study of the spermathecae enables the differentiation of these species.

Chiang et al. (2012) observed differences among the spermathecae of $P$. megistus, T. dimidiata, T. klugi, T. sordida, R. brethesi, $R$. nasutus, $R$. pictipes and Nesotriatoma bruneri. They highlighted that the spermathecae of $R$. nasutus and $R$. pictipes, which are long and tubular, extend to the posterior portion of the genital chamber; the schematic design matching the anatomical disposition of the two species in this 


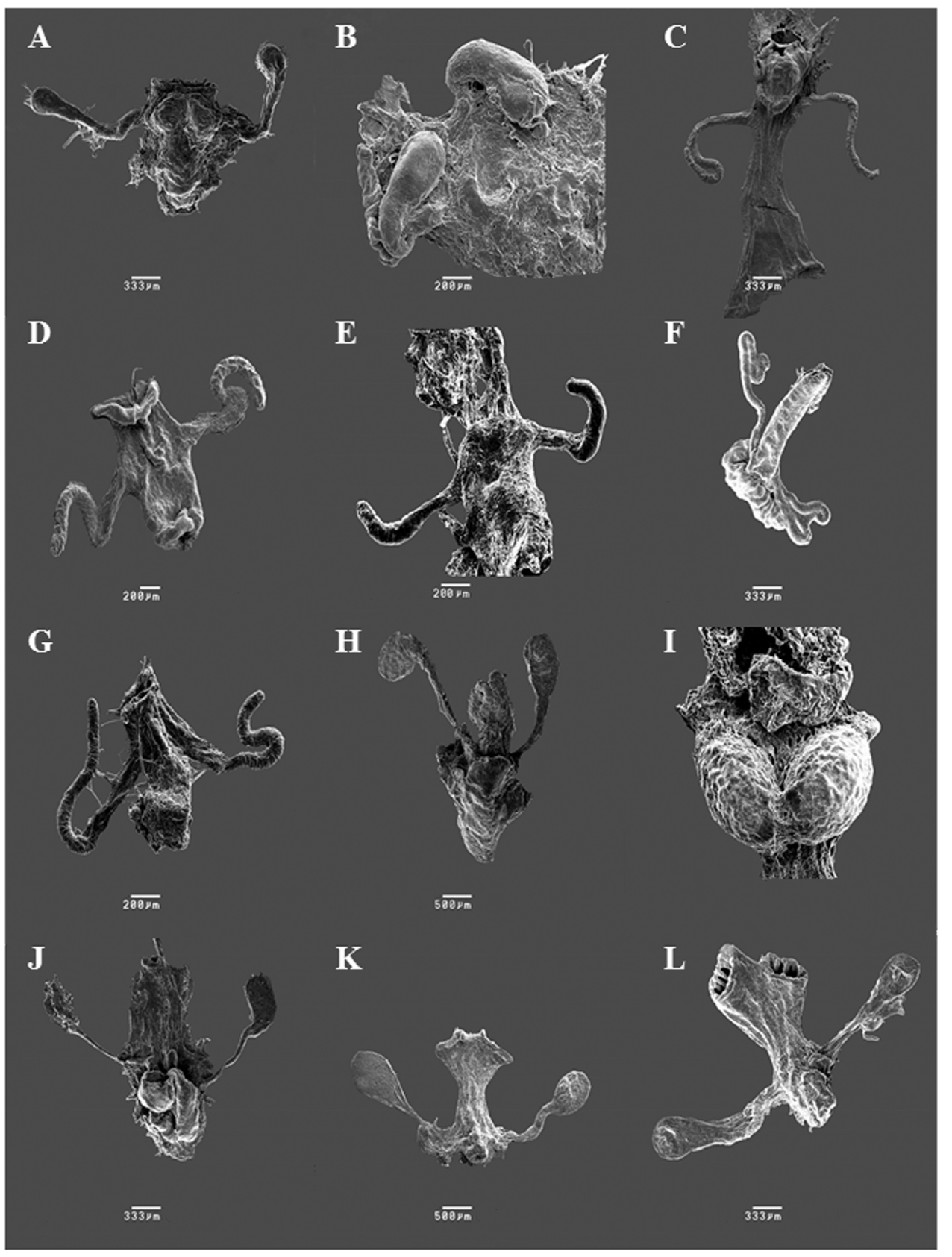

Fig. 3. Spermathecae of Triatominae observed by scanning electron microscopy (SEM) (A) P. lignarius, (B) P. megistus, (C) R. montenegrensis, (D) R. nasutus, (E) R. neglectus, (F) R. pictipes, (G) R. prolixus, (H) T. brasiliensis, (I) T. infestans, (J) T. juazeirensis, (K) T. sherlocki, (L) T. tibiamaculata.

study. The observations made by OM and SEM showed that the insertion of the spermathecae into the common oviduct of $P$. megistus is short and the final portion is oval. However, Chiang noted that the insertion of the spermathecae into the common oviduct in P. megistus is long and the final portion is round.

Specimens of the genus Rhodnius have tubular and sinuous spermathecae, whereas members of the genus Triatoma have spermathecae with thin initial portion and oval-shaped end portion, the same as the genus Panstrongylus. Of all twelve species studied, T. infestans is completely different from the other eleven species, since the body of its spermathecae is completely oval. The general conclusion is that the female spermatheca is different among the three genera as well as for each of the twelve species studied. This work highlights the importance of spermathecae for the reproduction of triatomines and demonstrates its validity as a taxonomical character to differentiate species.

\section{Conflict of interest}

All authors declare that they have no conflicts of interest related to this article.

\section{Acknowledgments}

The authors would like to thank Dr. Maria Tercilia Vilela AzeredoOliveira from São Paulo State University (Unesp/IBILCE) in São José do Rio Preto, Brazil, for providing the techniques used in the dissection of the triatomines. We would also like to thank Dr. José Maria Soares Barata (in memoriam), for obtaining and maintaining the colonies of Triatominae used in the study, and Dr. Cleber Galvão and José Jurberg for donating specimens of $P$. lignarius and T. tibiamaculata, which originated the colonies of those two species. 


\section{References}

Barth, R., 1973. Estudo anatômico e histológico sobre a subfamília Triatominae (Heteroptera, Reduviidae). Parte XXIII: O ovário de Triatoma infestans. Mem. Inst. Oswaldo Cruz 71 (1/2), 123-147.

Carvalho, D.B., Almeida, C.E., Rocha, C.S., Gardim, S., Mendonça, V.J., Ribeiro, A.R., Alves, Z.C., Ruellas, K.T., Vedoveli, A., da Rosa, J.A., 2013. A novel association between Rhodnius neglectus and the Livistona australis palm tree in an urban center foreshadowing the risk of Chagas disease transmission by vectorial invasions in Monte Alto City, São Paulo, Brazil. Acta Trop. 130, 35-38.

Chiang, R.G., Chiang, J.A., Sarquis, O., Lima, M.M., 2012. Morphology of reproductive accessory glands in eight species of blood-feeding Hemiptera (Hemiptera, Reduviidae) insect vectors of Chagas disease. Acta Trop. 122, 196-204.

Costa, J., Felix, M., 2007. Triatoma juazeirensis sp. nov. from the state of Bahia: northeastern Brazil (Hemiptera: reduviidae: Triatominae). Mem. Inst. Oswaldo Cruz 102, 87-90.

Costa, J., Correia, N.C., Neiva, V.L., Gonçalves, T.C.M., Felix, M., 2013. Revalidation and redescription of Triatoma brasiliensis macromelasoma Galvão, 1956 and an identification key for the Triatoma brasiliensis complex (Hemiptera: reduviidae: Triatominae). Mem Inst Oswaldo Cruz, Rio de Janeiro 108 (6), 785-789.

Davey, K.G., 1958. The migration of spermatozoa in the female of Rhodnius prolixus Stal. J. Exp. Biol. 35, 694-701.

Galvão, C., 2014. Vetores da doença de chagas no Brasil [online]. Curitiba: Sociedade Brasileira de ZoologiaVetores da doença de chagas no brasil [online]. curitiba: sociedade brasileira de zoologia. Zoologia: guias e manuais de identificação series. ISBN 978-85-98203-09-6 (289 p).

Gardim, S., Almeida, C.E., Takiya, D.M., Oliveira, J., Araújo, R.F., Cicarelli, R.M.B., Rosa, J.A., 2014. Multiple mitochondrial genes of some sylvatic Brazilian Triatoma: nonmonophyly of the T. brasiliensis subcomplex and the need for a generic revision in the Triatomini. Infect. Genet. Evol. 23, 74-79.

Justi, S.A., Russo, C.A.M., Santos-Mallet, J.R., Obara, M.T., Galvão, C., 2014. Molecula phylogeny of triatomini (Hemiptera: reduviidae: triatominae). Parasites Vectors 7 , 149.
Pérez, J.R., 1969. Estudio sobre la anatomía de Rhodnius prolixu. Rev. Venezulana de Sanidad y Asistencia Social 34, 9-98.

Pereira-Lourenço, A.S., Santos-Mallet, J.R., Freitas, S.P.C., 2013. Anatomy of the spermatophore in triatomines (Hemiptera, reduviidae, triatominae) and its applications to the study of chagas disease vector biology. Am. J. Trop. Med. Hyg. 89 (4), $775-780$.

Querido, J.F.B., Agirre, J., Marti, G.A., Guérin, D.M.A., Silva, M.S., 2013. Inoculation of Triatoma Virus (Dicistroviridae: cripavirus) elicits a non-infective imune response in mice. Parasites Vectors 2013 (6), 66.

Ricardo-Silva, A., Gonçalves, T.C.M., Luitgards-Moura, J.F., Lopes, C.M., Silva, S.P., Bastos, A.Q., Vargas, A.Q., Freitas, M.R.G., 2016. Triatoma maculata colonises urban domicilies in Boa Vista, Roraima, Brazil. Memórias do Instituto Oswaldo Cruz 111 (11), 703-706.

Rimoldi, A.R., Oliveira, R.C., Ceretti Junior, R., Lima, L., Almeida, L.A., Nascimento, J.D., Teixeira, M.M.G., Rosa, J.A., 2016. Trypanosoma cruzi isolated from a triatomine found in one of the biggest metropolitan areas of Latin America. Rev. Soc. Bras. Med. Trop. 49 (2), 183-189.

Rosa, J.A., Barata, J.M.S., Barelli, N., 1992. Spiracles of 5th instar nymphs in six species of Triatominae (Hemiptera, Reduviidae) using scanning electron microscopy. Memórias do Instituto Oswaldo Cruz, Brasil 87 (2), 301-302.

Rosa, J.A., Barata, J.M.S., Cilense, M., Belda Neto, F.M., 1999. Head morphology of 1st and 5th instar nymphs of Triatoma circummaculata and Triatoma rubrovaria. Int. J. Insect Morphol. Embryol. 28, 363-375.

Sousa, E.S., Von Atzingen, N.C.B., Furtado, M.B., Oliveira, J., Nascimento, J.D., Vendrami, D.P., Gardim, S., Rosa, J.A., 2016. Description of Rhodnius marabaensis sp. n. Hemiptera, Reduviidade, Triatominae) from Pará State, Brazil. ZooKeys 621 , 45-62.

Vöcking, O., Uhl, G., Michalik, P., 2013. Sperm dynamics in spiders (Araneae): ultrastructural analysis of the sperm activation process in the garden SpiderArgiopebruennichi (Scopoli, 1772). PLoS One 8 (9), e72660.

WHO, (2017).Available from: http://www.who.int/mediacentre/factsheets/fs340/en/ index.html. Cited: 31 august 2017. 